\title{
Public Processes Are Open for Play
}

TADEU MOREIRA DE CLASSE, Federal University of the State of Rio de Janeiro (UNIRIO), Brazil

RENATA MENDES DE ARAUJO, Mackenzie Presbyterian University (UPM) and University

of São Paulo, Brazil

GERALDO BONORINO XEXÉO, Federal University of Rio de Janeiro (UFRJ), Brazil

SEAN WOLFGAND MATSUI SIQUEIRA, Federal University of the State of Rio de Janeiro

(UNIRIO), Brazil

\begin{abstract}
As public services become digital and online, both the need to design digital public services closer to citizens' expectations and to provide ways to improve their participation and engagement increases. To participate and co-design, citizens must understand how the public service is delivered, but understanding service provision is challenging for non-technical subjects. This article argues that games can promote transparency of public service processes and citizens' understanding of them. We designed games related to three distinct public service delivery scenarios using Play Your Process (PYP), a method which translates business process models into game design artifacts. We also investigate players' ability to understand the process designed into these games through evaluation settings based on qualitative and quantitative analyses, using questionnaires and interviews. Results show that these games can help citizens understand the process execution aspects, with at least 95\% confidence through statistical analysis. This research is innovative by showing an approach to systematically design serious games describing public processes as a potential tool for citizen-government transparency and understanding of public process delivery, particularly in Brazil.
\end{abstract}

CCS Concepts: • Applied computing $\rightarrow$ Computing in government; • Information systems $\rightarrow$ Information systems applications;

Additional Key Words and Phrases: Public services, public services understanding, serious games, game design, Play Your Process, business process model, business process-based digital games

ACM Reference format:

Tadeu Moreira de Classe, Renata Mendes de Araujo, Geraldo Bonorino Xexéo, and Sean Wolfgand Matsui Siqueira. 2021. Public Processes Are Open for Play. Digit. Gov.: Res. Pract. 2, 4, Article 32 (December 2021), 18 pages.

https://doi.org/10.1145/3474879

This work was supported by the State of Rio de Janeiro Research Support Foundation (FAPERJ) under grant E-26/010.002458/2019 (to Tadeu Classe). It was also supported by the Brazilian National Council for Scientific and Technological Development (CNPq) under grants $n^{\circ}$ 313210/2019-5 (to Renata Araujo) and n³12039/2015-8 (to Sean Siqueira). Furthermore, it was partially supported by Mackenzie Presbyterian University Research Fund (to Renata Araujo).

Authors' addresses: T. M. de Classe and S. W. M. Siqueira, Siqueira, Federal Universitiy of the State of Rio de Janeiro (UNIRIO), Av. Pasteur, 458 - Botafogo, Rio de Janeiro - RJ, 22290-255, Brazil; emails: \{tadeu.classe, sean\}@uniriotec.br; R. M. de Araujo, Mackenzie Presbyterian University (UPM) Rua da Consolação, 930, Consolação, São Paulo SP, 01302-907 and University of São Paulo (USP), Rua Arlindo Béttio, 1000 Ermelino Matarazzo, São Paulo - SP, 03828-000; email: renata.araujo@mackenzie.br; G. B. Xexéo, Federal University of Rio de Janeiro (UFRJ), Programa de Engenharia de Sistemas e Computação (PESC), Avenida Horácio Macedo 2030, Centro de Tecnologia, Bloco H, Sala 319, Cidade Universitária, Rio de Janeiro - RJ - 21941-914, Brazil; email: xexeo@cos.ufrj.br.

Permission to make digital or hard copies of part or all of this work for personal or classroom use is granted without fee provided that copies are not made or distributed for profit or commercial advantage and that copies bear this notice and the full citation on the first page. Copyrights for third-party components of this work must be honored. For all other uses, contact the owner/author(s).

(c) 2021 Copyright held by the owner/author(s).

2639-0175/2021/12-ART32 \$15.00

https://doi.org/10.1145/3474879

Digital Government: Research and Practice, Vol. 2, No. 4, Article 32. Publication date: December 2021. 


\section{INTRODUCTION}

In a world connected by Information and Communication Technologies (ICT), organizations have expanded their opportunities to improve and innovate their business processes and individuals have been served by high-quality digital services $[1,73]$. Public organizations have focused on improving and digitizing their services $[56,58]$ and have been demanded to innovate through open dialogue with citizens, facilitating service delivery $[12,41,84]$.

Although society is believed to influence public services, it might not be a reality in practice $[17,23,58]$. Despite advances in research and practice in open government, it is still possible to find optimistic approaches to citizen participation in the provision of public services, assuming that the existence of a communication channel is enough to promote dialogue with society $[6,14,30,60,92]$. On the other hand, citizens may consider public services an uncomfortable need, which should be used quickly and with the least possible involvement [27, 82, 91]. Specifically in the Brazilian context, a recent report [23] shows that progress is still needed to innovate in better solutions to improve dialogue between citizens and public institutions in public service provision.

The lack of citizens' effective understanding of how governmental institutions provide their services may lead them to perceive these services as complicated, bureaucratic, and unnecessary. Understanding the operation, challenges, and limitations of a public service delivery process is crucial for citizens and public institutions to feel confident in dialogue, discussing and thinking about improvements and innovations in such services $[16,35,48]$. Some authors suggest that business process models [28] can be the basis for service transparency, understanding, and interaction with citizens [22]. However, process models are usually technical models, and their understanding by ordinary citizens requires their presentation in a simplified format $[5,29]$.

This research explores the potential of serious digital games to promote transparency of public service business processes. Due to their immersive and engagement potential, serious digital games have been used in several domains as tools to promote engagement and learning [37, 51, 52]. Users' engagement may lead to improvements and innovation in services. The use of serious digital games is also discussed as a social innovation strategy $[83,89]$, reinforcing the possible benefits of this approach.

In this article, we propose the conceptualization, development, and evaluation of games as a tool for supporting citizens in understanding public service processes. We assume that playing a game with content built on public services allows players to understand these processes actively. Additionally, public institutions may find in these games innovative opportunities for public service transparency. To investigate how serious games can be thought of as tools for transparency and understanding of public service delivery processes, this research raises two main questions: (1) "How can public service delivery process games be designed?"; and (2) "Can these games increase citizens' understanding of public service delivery?"

To answer the first question, our research follows a Design Science Research methodology [62], where investigations contributions are obtained by constructing artifacts and their evaluation in context. The research is based on previous work, which defines a game design method named Play Your Process (PYP) [24]. Using the PYP, it is possible to develop systematically serious digital games based on business process models, which are often used in organizational management, including public management. The games generated using the PYP are serious digital games based on business processes [24], and we argue that they convey process understanding playfully. In this article, we present the design of three serious digital games based on distinct business process models of public services in Brazil using the Play Your Process.

For the second research question, the quasi-experiments evaluate whether the games developed help citizens understand how services are provided (their process), a path to their potential to develop service transparency and citizens' empathy and engagement. Results show that, by playing the game, citizens understand the public process aspects with at least $95 \%$ confidence through statistical analysis.

This article is structured as follows: Section 2 summarizes the conceptual background comprising Business Process Management fundamentals and the concept of business process-based digital games; Section 3 discusses 
related work; Section 4 details three public process-based digital games for distinct public processes in Brazil; Section 5 describes the evaluation and its limitations, and brings a discussion; finally, Section 6 concludes the article.

\section{BACKGROUND}

\subsection{Open Government}

Open government is defined as a set of government initiatives based on the principles of transparency, integrity, accountability, and stakeholder (including citizens) participation [58]. The interaction between citizens and government using ICT has been highly explored by governments around the globe, especially in the delivery of public services and in the involvement of citizens in public policy decision-making.

It has been argued that citizen engagement and participation improve at a progressive scale where, at each level, citizens are increasingly empowered in their possibilities for participation, discussion, and decision-making in government processes and issues [36]. Different relationships between government and citizens can be configured through this scale: at lower levels, government and citizens have very distinct responsibilities and roles; and at higher levels, roles and responsibilities are mixed and interchangeable. Through the use of ICT, different levels of social participation in government affairs can be characterized: (1) information and services consumption; (2) collection of public opinion; (3) transparency and accountability of government information, processes, and actions; (4) indirect decision making through deliberative democracy; and (5) direct democracy itself, where each level increases citizen participation, discussion, and decision-making in the public business decision-making process [26].

Open government is grounded in the advancements of digital transformation [73] in governments and the potential for connectivity provided by the Internet, especially social media platforms. The interplay between cyberspace and contemporary cyberculture has provided changes in government and democratic practices, which emerge from the new possibilities of public opinion and empowerment through technology use. Open government is the possibility of political interaction and public management through technology, enhanced by the Internet, bringing together aspects of today's society-connected, convergent, informed, and collaborative-and the challenges faced by government institutions to follow and serve this society [8].

This research focuses on the Brazilian context. The Brazilian government and its institutions have performed significant legal and operational efforts to improve public service delivery [34, 42, 54, 59]. As a consequence, most public institutions provide basic information about their services online nowadays. Indeed, the last survey performed by the Brazilian Internet Steering Committee [23] about using ICT in the Brazilian public sector showed that $66 \%$ of the local governments provide public services through websites. The types of service offered through these websites are: downloadable documents or forms (69\%); submitting forms (43\%); registering for public exams or courses (38\%); generating invoices (37\%); checking ongoing proceedings (29\%); obtaining tax payment slips (26\%); obtaining official documents (22\%); and scheduling appointments, assistance, and the like $(13 \%)$. The type of resources offered to citizens on those websites is content to search engines (66\%), videos (35\%), requesting services $(32 \%)$, real-time broadcasts $(16 \%)$, and audio or web radio $(11 \%)$.

In addition to service complexity and limited channels, Brazilian citizens needing access to public services are often poor, elderly, or even illiterate, i.e., citizens unable to understand most terms and legislation. Such a scenario entails further challenges for public bodies concerning operating effectively through social media or online channels. Therefore, in practice, it is common to find private professionals specialized in helping citizens cope with the burden of public services delivery, which may help, but simultaneously, facilitates corruption.

Based on these observations, we propose the conceptualization, development, and evaluation of games as a tool for supporting citizens in understanding public service processes. We assume that playing a game with content built on public services allows players to understand these processes actively, arouse their interest in understanding them, and critically reflect on them. In this way, players develop literacy in public services, thus 
enabling them to correlate the game content with their personal experiences and share and discuss suggestions for process improvements with related social groups. Additionally, public institutions may find in these games innovative opportunities for public service transparency.

\subsection{Business Process Management}

The discipline of analyzing how work is performed to ensure positive results and opportunities for improvement is known as Business Process Management (BPM) [28]. This knowledge area combines principles, methods, and tools to design, analyze, automate, and monitor the organizational processes' performance. Business process modeling is an essential task of the BPM life cycle, consisting of the formalization of a diagram representing objectives, actors, activities, execution flow, resources, and products of an organizational process [28].

Public organizations occasionally make use of BPM approaches to improve service management. For example, the vulnerable citizen management processes in Switzerland [31]; the modeling and renewal of processes in the government of Slovenia [46]; the participation platforms associated with BPM systems in public administration in Italy [25]; among others [11].

One research strand in the BPM area is the possibility of extending BPM to the external organizational environment, allowing organization clients to take part in improvements and innovation process-Social BPM $[66,71,78]$. Pflanzl and Vossen [66], Rangiha and Karakostas [71], and Afandi [3] point out that, for external actors to feel able to interact and contribute to the organizational processes improvement, they must manage to understand how the process was defined and is performed.

The approach presented in this article is based on the assumption that public organizations might use business process management as an alternative for managing their public service delivery processes $[11,77,85]$. It is also assumed that public organizations might benefit from improving transparency and extending their processes to external actors as a public participation innovation endeavor [32, 57]. However, to guarantee process transparency and citizens' interaction, it is necessary to determine manners to help citizens understand the service delivery process in detail.

\subsection{Business Process-Based Digital Games}

The digital games industry currently drives much of the world's creative and technological economy [49]. McGonigal [51] argues that games can break existing mental models that separate work and fun. The author discusses the idea that challenges fuel human beings' motivation and engagement, and games are perfect for that, even in the workplace.

The kind of games that interests this research is serious digital games [2,52] or games with a purpose [87]. A game with purpose has as its secondary objective (the main one is the challenge and fun) to teach something to the player [74]. Games with a purpose have a proven potential to improve the training programs' effectiveness and increase productivity and problem solving [13, 64].

Business process-based digital games are games with a purpose that present a business process in a playful, funny, and engaging manner, and that allow players to understand and learn how the process works, as well as to develop an awareness of the process objectives, practices, values, challenges, and limitations [24]. The Play Your Process method was developed to carry out the design of business process-based digital games and is fully described in [24]. It organizes the whole business process-based digital game development through game engineering concepts, guiding game designers from the game conceptualization to evaluation, starting from a business process model. The key activity in the method is the possibility of semi-automatically translating elements of a process model into game design elements, making the game design directly adherent to the process definition. A brief description of how this conceptual mapping is performed is presented in Table 1.

A business process-based digital game is, to some extent, an "dventure game" where players can effectively "play" the adventure of performing the organizational process. For example, consider the process model depicted 
Table 1. Mapping Guidelines between Process Model Elements and Adventure Game Elements

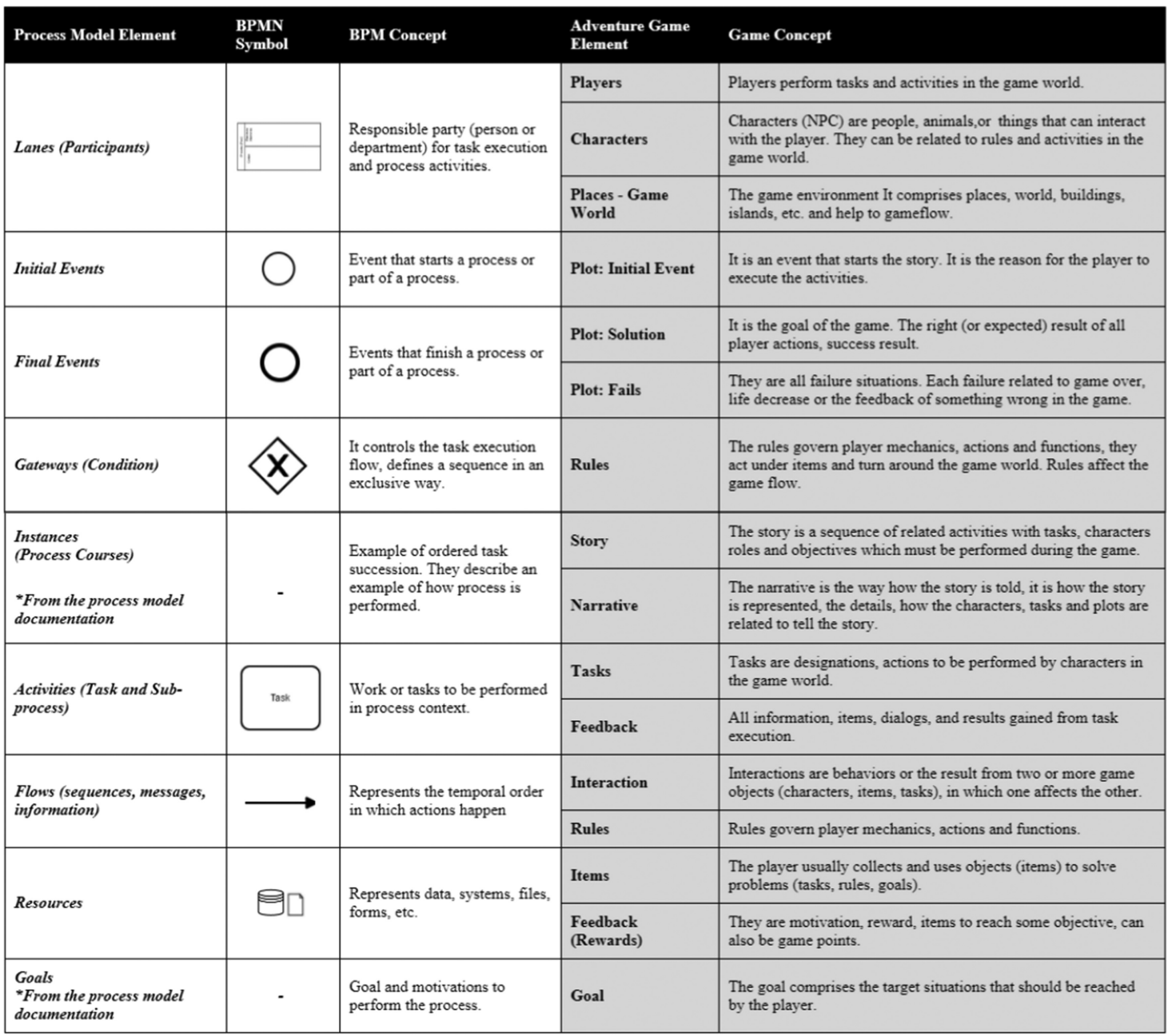

in Figure 1, which describes part of the process conducted in a Brazilian police department for finding missing persons, comprising case analysis, and its inclusion into the police department information system. To design this process as a game, the method guides the designer to map process elements into game elements: events ("Missing person reported", "Answer Closed", and "RO is sent") as start and winning condition of the game; actors ("Citizen" and "Police Station") as characters or scenarios in the game; activities (e.g., "Person Welcome" and "Case Analysis") as game tasks or phases; resources (e.g., "ROWEB" and "Documents") as tools or achievements in the game; and rules and decisions in the process into decisions in the game. Following this process mapping activity suggested by the method, it is possible to build a game to allow the player to go through the process execution as defined in the model as an "dventure" game, and eventually, to learn about the process designed in the game. The game designed using the method for this public process is presented in the next section: The Missing Person Game.

Other activities besides process-game mapping are required to complete the game design: to understand the process context, aims, and expected organizational results (context analysis); to create the game concept where 


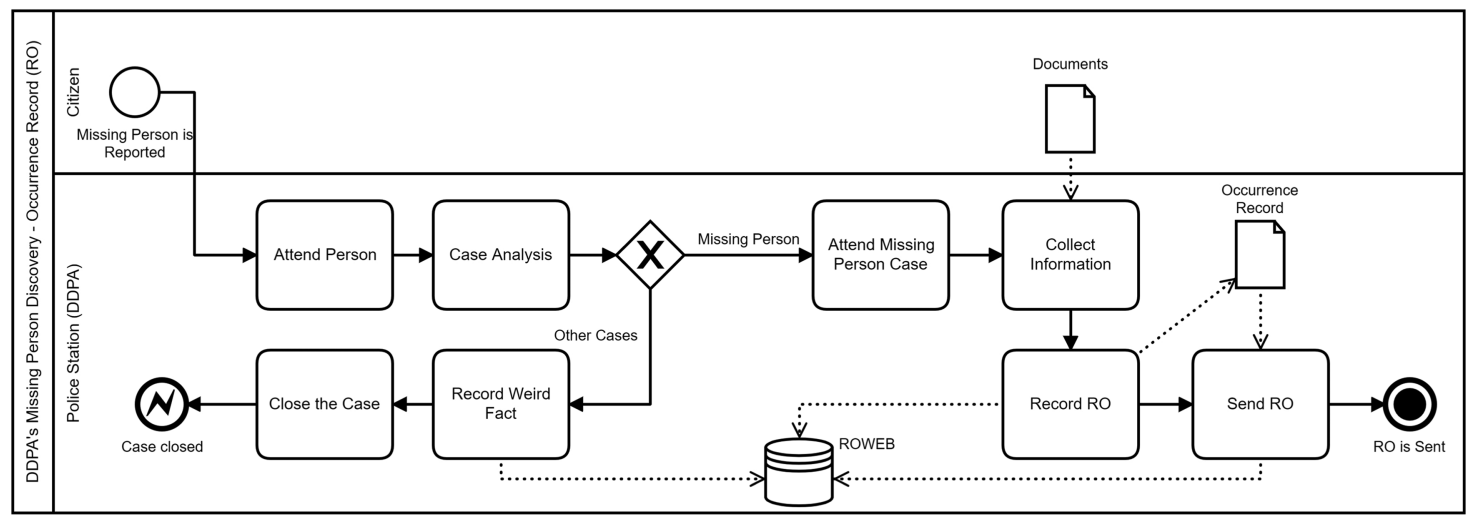

Fig. 1. Example of a business process model (Missing Person Discovery’s BPMN Model).

designers use their creativity to create an enjoyable game by defining its mechanics and aesthetics game project step; to work on prototyping and development, evaluation and publishing. Previous work [24] describes the method in detail and discusses how it can be an approach for organizations to produce games systematically based on organizational business process models.

\section{RELATED WORK}

It is possible to discuss related work from three perspectives. First, we can find previous research discussing games as a tool for BPM learning, i.e., to use games to train BPM students or professionals. Ribeiro et al. [72] describe a game called ImPROVE, aimed at improving BPM learning, using the real scenario of a Portuguese hospital triage system. Santorum [76] proposes a method based on serious games, aiming to identify, simulate, and improve an organizational process. The worker can play the game, learn with it, and suggest process improvements. Kutun and Schmidt [47] propose a board game to help learning process modeling. Winter et al. [88] investigate whether serious games have a positive, immediate, and follow-up impact on process model comprehension, based on the use of a game which, in its levels, the players need modeling BPMN ${ }^{1}$ models for specific situations. Rosenthal and Strecker's [75] work is based on a serious game to learn how to make business process models. At the same time, Pflanzl and Vossen [67] argue how process models can be considered games, supported by gamification elements for learning purposes. Although these solutions are thought to promote business process modeling understanding or practice using games, they are targeted to a technical audience, i.e., for those who must learn to execute or manage business processes. Our research aims not to provide citizens with BPM skills or process learning, but to provide them with a higher level of service delivery transparency.

Second, it is possible to find research addressing the use of games for the involvement of citizens in civil proceedings. Poplin [69] evaluates the potential of serious games to support citizen participation in urban planning. A game was designed for citizens to contribute with ideas for improving the urban planning of Billstedt (Hamburg, Germany). They could build their own business in a specific location and discuss issues that could arise with other citizens, helping government decisions. Lounis et al. [50] evaluate the impact of two distinct game elements (incentives and community collaboration) in user participation in a gamified public service. The use of digital games is pointed out as a social innovation strategy in Hong Kong [89], where digital games were used to serve the local community in many areas such as educational, social, and environmental issues. The author highlights the opportunity for designing serious games for public services, like postal services, public

\footnotetext{
${ }^{1}$ BPMN: https://www.omg.org/bpmn/.
} 
administration, parking spaces, and the like. Buheji et al. [18] argue about the opportunities for government transformation arising from gamifying essential services in education, management, sanitary services, social insurance, and so on. Hassan [38] is concerned about the co-design of public service and the promotion of civic engagement through gamification guidelines into participative platforms. Aguilar et al. [4] present a city simulator game that generates emergent properties, which could be used by smart cities for city planning, to make collective decisions, and to promote citizen electronic participation. Similarly, Caluwé et al. [20] show games for public policy development, using simulation.

Third, we can find research discussing games and gamification as tools for engaging public servants in policies and procedures. Bharosa et al. [15] discuss role-playing games as tools to facilitate service delivery simulation, learning, awareness, and engagement and participation in service improvements. Kleiman [44] and Kleiman et al. [45] analyze the effects of a game [43] on the intentions of public servants to publish data in open format. Based on theoretical models such as the Theory of Planned Behavior and the Technology Acceptance Model, they conducted quasi-experiments to evaluate the change in public servants' intentions before and after playtests in São Paulo and Brasília, Brazil. Experiments confirmed an increase in participants' willingness to support open-data policy-making and their perception of benefits. However, they could not confirm that playing the game resulted in more data knowledge management and ways to open data. Nevertheless, the work reports that "By performing the routines in the game and understanding that opening data is less complex than they imagined, their perception change indicates that this is likely to be a relevant effect of the game ..." [45]. Most importantly, the research states that "The outcomes suggest that gaming is a suitable instrument for knowledge transfer and for creating awareness of possibilities for opening governmental data ..." and that "... other civil servants with less previous knowledge and experience might profit more from this aspect [learning] of the game ...” [45].

The previously described research focuses on promoting citizen engagement and participation through gamification procedures or engaging servants in strategic tasks. They do not precisely address designing games specifically to support public service delivery and to help citizens understand how public administration is provided, as expected in this research. Similar to what was observed by Bharosa et al. [15] and Kleiman et al. [45], we aim to evaluate if games can be used as knowledge transfer mechanisms, bringing better transparency, and developing awareness and understanding of how public organizations provide a public service.

\section{DESIGNING PUBLIC PROCESS-BASED DIGITAL GAMES}

Design Science Research (DSR) was the epistemological-methodological approach used in this research. DSR aims to investigate the artificial (artifacts) and its behavior, both from the scientific and the application point of view $[10,39,81]$. In an overall view, DSR may be described as a process of creating artifacts to solve problems, evaluate the designed artifact in its context of use, and communicate the results [19]. The research design can be summarized in four main components [62,68]: the Contextualized Problem; the Artifact itself; Behavioral Conjectures; and Emprical Evaluation.

As described in previous sections, open government is our research context, where digital games have been proposed as a platform for citizen-government transparency and understanding. We address the design of public service-based digital games, i.e., serious games that implement the public service delivery process and help citizens understand the process by playing the game.

An acceptable artifact to solve our research problem is to design games where players can have the playful experience of participating in the public service process as modeled and performed by the public organization. By using the artifact, citizens would understand how the public organization performs activities, uses resources, follows the rules, and so on, to provide them with a specific service. Therefore, the research proposes designing public process-based digital games contextualized in specific Brazilian public services. We used the Play Your Process method to explore how public organizations could manage to create games based on their public services business models as an alternative for providing citizens transparency and understanding of public services. 
Sections 4.1, 4.2, and 4.3, briefly describe three public process-based serious games designed in this research for specific Brazilian public services. It is important to emphasize that each game enacts the process used to deliver the service as defined and modeled by each public organization.

Our behavioral conjectures are grounded on the assumption that serious games have the potential to promote learning. Therefore, by playing public process-based digital games, players would understand the process implemented in the game. Therefore, empirical evaluation was conducted through quasi-experiments to evaluate whether the games developed help players understand how services are provided (their underlying process).

\subsection{The Missing Person Game}

The missing person discovery service is performed by the police department in Rio de Janeiro, Brazil. The service and its steps are unknown by the citizens [40], which leads to confusion and disappointment in service provision. Based on interviews with police representatives at the Missing Person Police Department (DDPA), we modeled the process (Figure 1) and designed the game based on this model. The game narrative follows common cases the police department faces, like a missing boy who got lost in the subway while going to school.

The game puts the player into the role of a police officer at the police department (Figure 2(A)), and he/she must correctly perform the process tasks. At the same time, he/she attends to different citizens reporting missing persons. The game allows the player to experience the process used in the police department, considering the resources available to perform the process and facing the process challenges and difficulties. The cases that must be solved are based on real-life situations described by the police department staff, leading the player to contact with several social issues involved in the process (missing children, the elderly, mentally-ill persons, and criminals). The game is over when the player cannot solve the case in a specific timeframe or the character gives up the service.

The player must collect information about the missing person. As in the real process, the officer must calm the citizen down while he/she tries to get enough information (e.g., ID, address, eye color, skin, birthmarks, and clothes) to find the person as fast as possible (Figure 2(B)). The player must use the resources available for performing the tasks, such as information systems, and face frequent problems while using these resources (for instance, finding the password to access the system). Player success in the game comprises finding the missing person by performing the right task.

\subsection{The SUS-Card Game}

The Brazilian Unified Health System (SUS) aims to provide Brazilians with full and unrestricted access to health services. Every citizen has the right to have the National Health Card, or as it is known, the "SUS Card", to have access to procedures performed within the scope of SUS [53].

The process to request the SUS Card follows well-defined steps: identification and collection of documents, card withdrawal schedule, attendance at a health unit issuing the card, data validation at the health unit, card printing, and card release. Although it does not seem complex, its execution has flaws, mainly due to improper understanding by citizens or lack of information on how to obtain the benefit. The game design was based on a business process modeling using the information and steps described in the Brazilian Ministry of Health portal [53].

The game seeks to highlight the consequences of not having the SUS Card. During the game, the player faces typical Brazilian health problems/diseases caused by bees, snakes, mosquito or spider bites, leptospirosis, and other injuries, which decrease the player's health level if he/she does not have the SUS card and lead to death if this level reaches zero. The player must collect important documents at each game level by solving specific puzzles (Figure 3(A)). One of these puzzles is finding a way to have access to a computer to register into the Brazilian Ministry of Health portal. By registering into the system, the player earns the possibility of following a shorter path with a bonus. The game ends in victory when the player gets his/her SUS Card. 


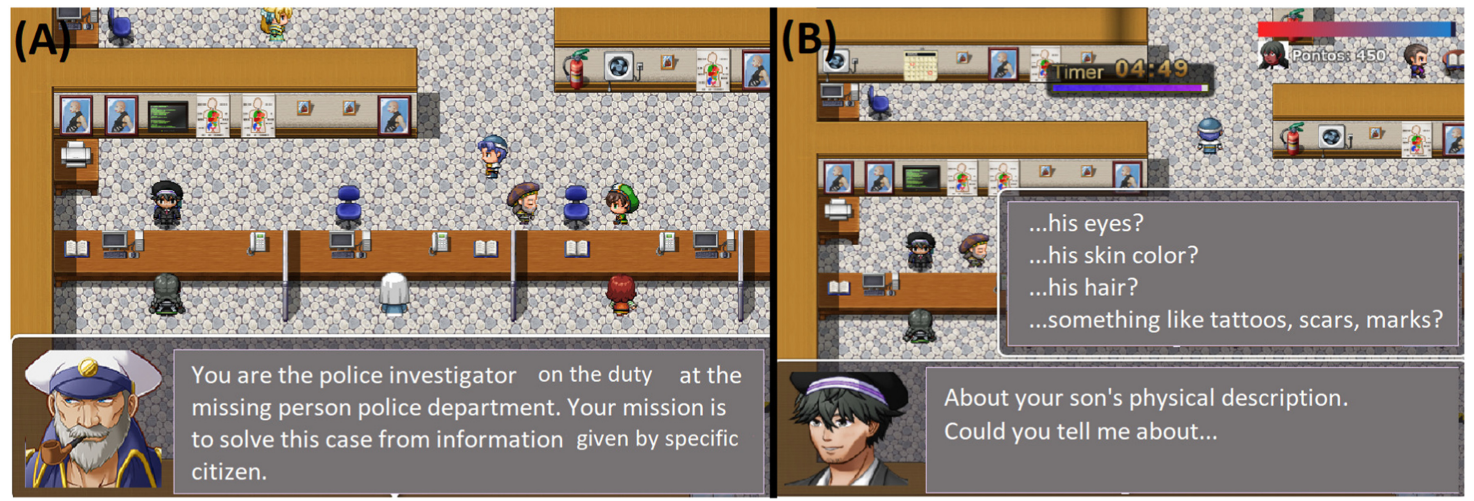

Fig. 2. (A) Game introduction telling the player that he/she is the police officer and the aims in the game. (B) Police officer investigation: Requesting a physical description of the missing person.

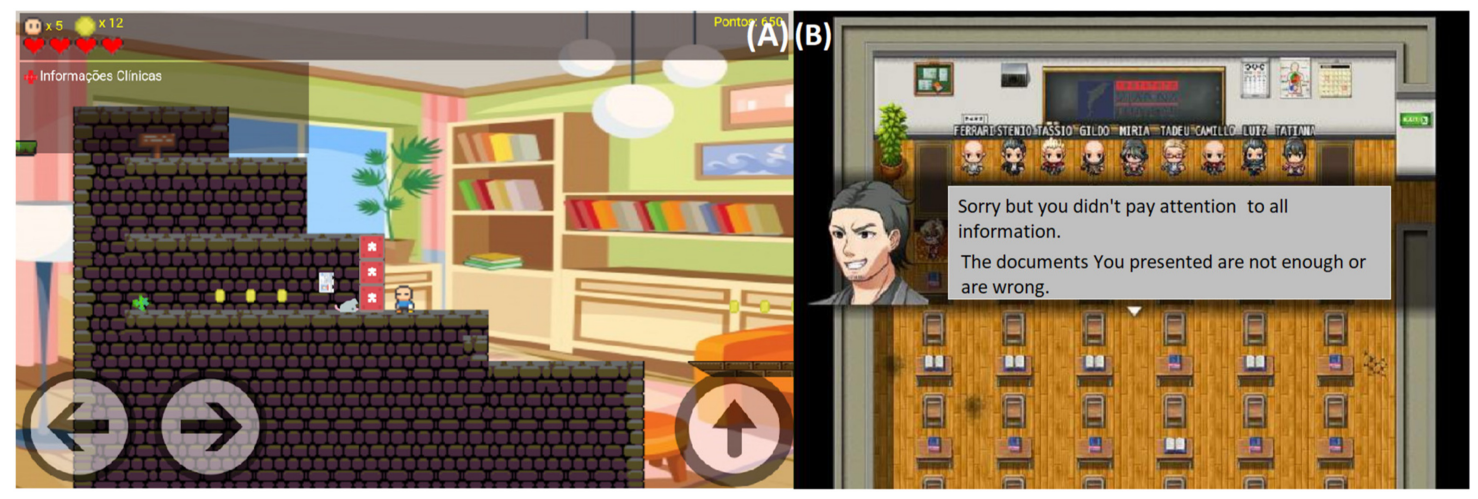

Fig. 3. (A) SUS-Card Adventure - Document search task. (B) PROUNI Game - Documents are not enough.

\subsection{The PROUNI Scholarship}

The PROUNI is a student loan program that can be requested by Brazilian citizens who wish to enter higher education at a private university. There are steps to be carried out: document preparation, ENEM (National High School Exam) completion, choosing the desired educational institution, and family income analysis. The process has steps that vary according to the candidate profile (candidates with disabilities or different nationalities) $[33,70]$.

Although the PROUNI application process is not complex, its steps may be confusing to students. There are portals and face-to-face services at educational institutions to answer questions. However, when a scholarship is awarded, it is necessary to prove the information previously provided in the registration. It is very common for candidates to lose their benefits due to forgetting documents or providing inaccurate information [70]. Based on the information available on the Brazilian government service portal [33], the service process was modeled in BPMN, which served as the basis for the game design.

The game puts the player into the role of a high school student who dreams of a college degree in his city. The game starts at the student's home. His/her mother wakes him/her up to remind the student about the deadlines of the PROUNI application (a typical Brazilian family situation). As in the SUS-Card game, the player must solve puzzles to collect all the documentation needed for the application and submit the application to the government 
information systems correctly. The player wins the game if he succeeds in taking all the documents needed to the university where he/she applied for the program (Figure 3(B)).

\section{EVALUATION}

We evaluated each game using quasi-experimental methods to analyze if it promoted the players' public service process understanding. According to Campbell and Stanley [21], quasi-experimental methods are an empirical nature class of studies, less controlled than traditional experimental studies, and without a randomized group selection of participants. As in traditional experiments, the quasi-experimental studies follow the methodological steps: (1) study definition; (2) study planning; (3) study execution; (4) analysis and interpretation; and (5) conclusions $[79,90]$.

\subsection{Studies Definition}

The definition presents the study goal, which is described following the GQM (Goal-Question-Metric) [9] approach: analyzing the business process-based digital games with the purpose of evaluation; in what regards the increase of player's understanding; from the players' perspective; and in the context of playing the business process-based digital game.

\subsection{Studies Planning and Execution}

This set of studies focused on transferring knowledge and helping players understand the process designed in the game. The study participants were collected by convenience sampling. We used convenience sampling because, in a general way, any Brazilian citizen is a potential player of these games. Even if they do not use the service in their lives, they must have the right to know how the process is provided.

In the PROUNI game, 25 participants attended the study. They were senior high school students of a Brazilian private school, aged around sixteen to nineteen years old, males and females. For the SUS-Card game, 31 participants participated in the study, and for the Missing Person Game, 83 participants attended the study. In both studies, the participants were college students from different Brazilian universities, males and females of various ages. All of these participants were volunteers invited to participate, and there were no rewards for the participation.

Based on the study definition, and as an experimental study, we postulate the null and alternative hypotheses as:

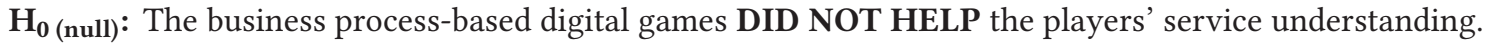

$\mathbf{H}_{1}$ (alternative): The business process-based digital games HELP the players' service understanding.

We designed this quasi-experimental study to be a pre-test and post-test evaluation $\left(\mathrm{O}_{1} \mathrm{X} \mathrm{O}_{2}\right)$ [90], i.e., there were moments to measure the participant's knowledge about the process represented in the game: in the former, a third party applied a questionnaire before participants played, and in the latter, applied a questionnaire after they played. Afterward, the answers to both tests are compared. Even though the studies involved a distinct group of players who are invited to play the games, every study application followed the same structure (steps): (1) the pretest questionnaire (fifteen minutes); (2) the gameplay session (thirty minutes); and (3) a post-test questionnaire application (fifteen minutes). The evaluations were executed independently-in each game evaluation, the study was applied individually and without interference among the participants-and on different days.

The Study Instrumentation is based on a questionnaire designed to measure the individual player's understanding of the public service process designed into the games. The questionnaires comprised a set of questions, which evaluate the players' understanding of the main process tasks. We designed each question based on Bloom's Taxonomy principles [7], which organizes three dimensions of knowledge: I can remember (R), I can understand (U), and I know how to apply (A). For each question, we used a Likert scale-based approach ranging from five levels: 
0 (I totally disagree) to 4 (I totally agree). The player's understanding $(\mathrm{K})$ at each question was calculated using a pondered mean: $K=[(R * 1.0)+(U * 2.0)+(A * 3.0)] / 6.0$.

In the execution step, we performed three different evaluations for each game. As allowed in quasi-experimental studies, the participants' selection was by convenience: (1) Missing Person Game: 83 participants; (2) The SUSCard Game: 31 participants; and (3) The PROUNI Scholarship: 25 high school students.

5.2.1 Threats of Validity. The main threat of conclusion to these quasi-experiments could be the power of statistical methods used in the analyses due to so many of them and different ways to use them. We applied statistical methods, more adjusted for each situation, to mitigate this threat based on data scales, means, and data normality behavior.

As internal threats, we enumerate: (1) participant wear due to time expended in the study-to decrease this threat, we fixed all the evaluation in 60 minutes total time, (2) threat of study construction due to the researches expectation-to decrease the threat, a third party applied the questionnaires, and (3) threat of training-to decrease it, the study was explained in the beginning, and all doubts were answered.

\subsection{Analysis and Interpretation}

We analyzed all data by quantitative approaches, using the software $R$ Statistics 3.6.1. The data summary considered descriptive and inferred statistics. We extracted all information exclusively from the participants' answers in the questionnaires, and the analyses were guided to verify the research hypothesis. In all of the evaluations, the statistically significant level assumed was $95 \%$ (alpha $=0.05$ ).

First of all, the box-plots depicted in Figure 4 summarize these results. The graphs show the player's understanding $(\mathrm{K})$ in pre-test and post-test questionnaires for each process activity. As it is possible to observe, in general, all main process tasks represented in each game had improvements in the players' understanding. Figure 4(A) shows improvements in players' understanding of the missing person service. Before playing the game, the participants' median understanding did not exceed 1.0 ( 0.5 best case - Collect Case Information). After playing the game, the minimum score surpassed 2.0 (3.0 in Collect Case Information). Figure 4(B) shows the evaluation results of the "SUS-Card Game", wherein the pre-test, the understanding (K) reaches 2.0 points in the best case (Get and Separate Documents). In the post-test, the worst score is close to 3.5 points (SUS Card Previous Registration). Moreover, Figure 4(C) shows The PROUNI Game results where it is possible to observe an improvement in the process' understanding in all process tasks.

We used statistical inference tests to evaluate this perception of improving the players' understanding shown in Figure 4, which validates the alternative hypothesis $\left(\mathrm{H}_{1}\right)$. All sample sets of the three evaluations were submitted to statistical tests (Table 2). They were submitted to the Shapiro-Wilk normality test (the most appropriate normality test due to the number of participants) [80], and all the samples presented non-normality behavior (pvalue less than 0.05$)$. Due to the non-normality behavior, the Wilcoxon test [55] was used to determine whether the games supported an increase of understanding and the Vargha Delaney $\left(A_{12}\right)$ [86] test to observe the odds of the behavior happening in each case (effect size).

Therefore, observing Table 2 and Figure 4, it is possible to say that with at least $95 \%$ confidence (considering alpha $=0.05$ ), the games helped the public service understanding in each game evaluation (accepting the alternative hypothesis $\left.-\mathrm{H}_{1}\right)$. Observing the effect size provided by the $A_{12}$ test, it is also possible to see that the post-test presented better results than the pre-test.

\subsection{Limitations}

All the business process-based digital games described above gamify actual public processes from distinct public institutions in Brazil. However, only The Missing Person Game was designed with the participation of representatives from the public institution. The other games were designed from a business process modeled by the research team based on each institution's website information. Although the participants in each game 
A) Missing Person Game

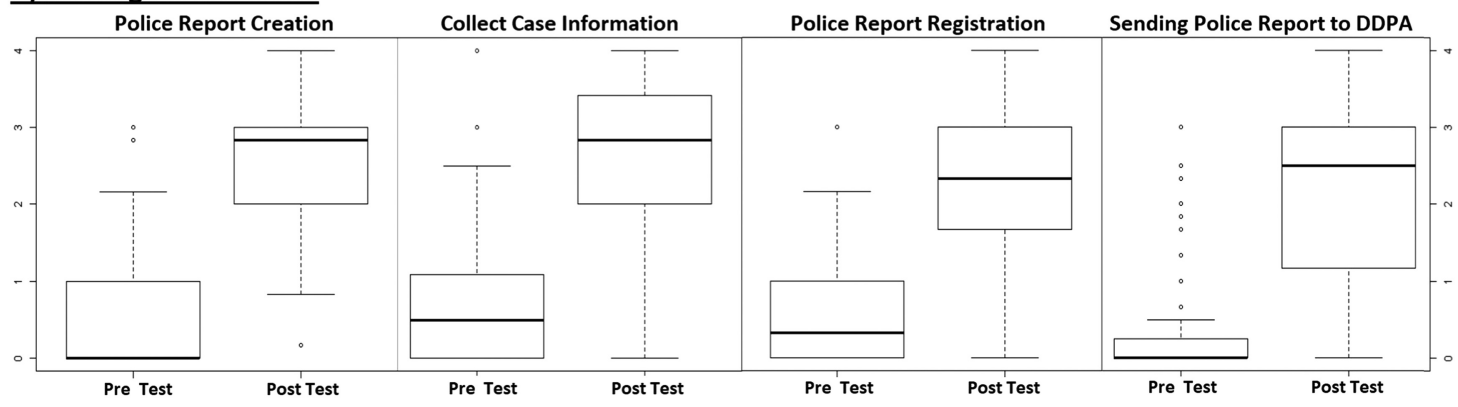

B) SUS-Card Adventure

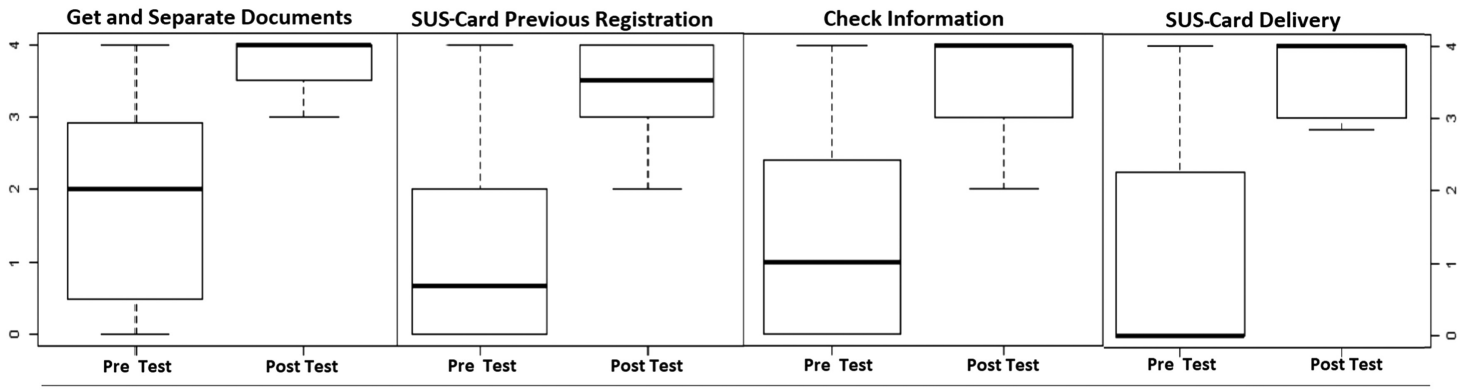

C)The PROUNI Game

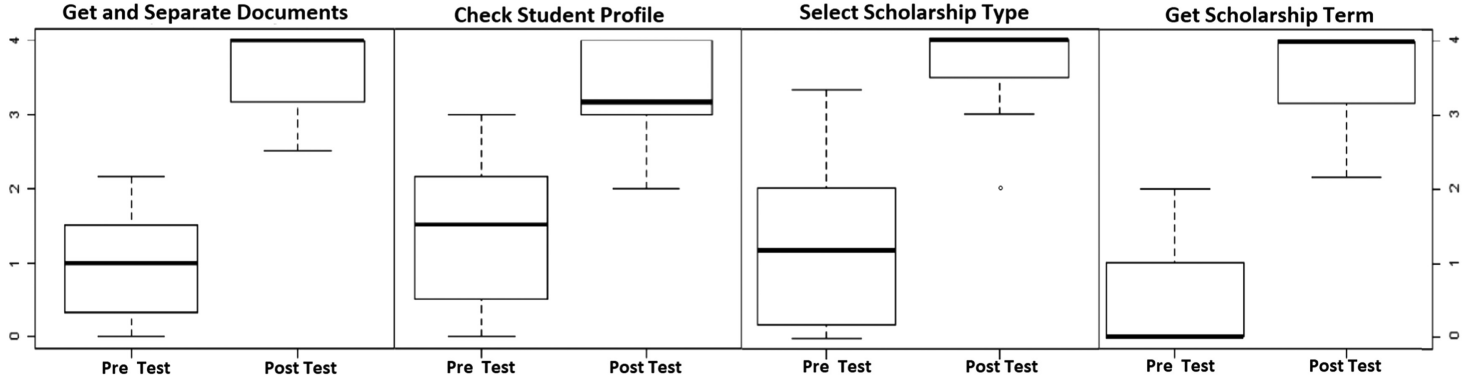

Fig. 4. Pre and post-test results for each game evaluation.

evaluation are real citizens and potential users of each service, they do not represent the full diversity of the Brazilian population. Additionally, all the games were evaluated in a controlled setting, which means the participants were not necessarily willing to have the service provided. The motivation to use the game was mainly the invitation to take part in the evaluation.

\subsection{Discussion}

Based on the results previously described, it is possible to answer our research questions as follows:

(1) "How can public service delivery process games can designed?"

We illustrated the design of distinct public process-based digital games that enact organization process models defined for each public service, using the PYP. The method was essential for designing games fully aligned with the process specification and showed some potential to be a tool for systematically designing and redesigning games for public services. Indeed, this research concludes that this kind of game can be designed. However, 
Table 2. Inferential Statistics to the Three Game Evaluations

\begin{tabular}{|c|c|c|c|c|c|}
\hline Game & Task Evaluated & $\begin{array}{c}\text { Case } \\
\text { Study } \\
\text { Test }\end{array}$ & $\begin{array}{r}\text { Shapiro-Wilk Test } \\
(\text { alpha }=0.05)\end{array}$ & $\begin{array}{l}\text { Wilcoxon Test } \\
(\text { alpha }=0.05)\end{array}$ & $\begin{array}{l}\text { Vargha Delaney } \\
(\text { A12) Test }(\%)\end{array}$ \\
\hline \multirow{8}{*}{$\begin{array}{c}\text { The Missing } \\
\text { Person } \\
\text { Game }\end{array}$} & \multirow{2}{*}{ Police Report Creation } & Pre-test & $1.75 \mathrm{e}-11$ & \multirow{2}{*}{$2.1 \mathrm{e}-22$} & 6.84 \\
\hline & & Post-test & $1.34 \mathrm{e}-04$ & & 93.16 \\
\hline & \multirow{2}{*}{ g Collect Case Information } & Pre-test & $1.13 \mathrm{e}-09$ & \multirow{2}{*}{$4.0 \mathrm{e}-20$} & 8.64 \\
\hline & & Post-test & $2.20 \mathrm{e}-02$ & & 91.36 \\
\hline & \multirow{2}{*}{ Police Report Registration } & Pre-test & $1.26 \mathrm{e}-08$ & \multirow{2}{*}{$1.2 \mathrm{e}-18$} & 10.39 \\
\hline & & Post-test & $5.17 \mathrm{e}-04$ & & 89.61 \\
\hline & \multirow{2}{*}{$\begin{array}{l}\text { Sending Police Report to } \\
\text { DDPA }\end{array}$} & Pre-test & $2.74 \mathrm{e}-12$ & \multirow{2}{*}{$4.1 \mathrm{e}-22$} & 8.07 \\
\hline & & Post-test & $2.08 \mathrm{e}-03$ & & 91.93 \\
\hline \multirow{8}{*}{$\begin{array}{l}\text { The SUS- } \\
\text { Card Game }\end{array}$} & \multirow{2}{*}{ Get and Separate Documents } & Pre-test & $2.57 \mathrm{e}-10$ & \multirow{2}{*}{$6.17 \mathrm{e}-09$} & 8.17 \\
\hline & & Post-test & $5.18 \mathrm{e}-10$ & & 91.83 \\
\hline & \multirow{2}{*}{ SUS-Card Previous Registration } & Pre-test & $8.87 \mathrm{e}-05$ & \multirow{2}{*}{$1.33 \mathrm{e}-09$} & 5.99 \\
\hline & & Post-test & $2.50 \mathrm{e}-05$ & & 94.01 \\
\hline & \multirow{2}{*}{ Check Information } & Pre-test & $1.72 \mathrm{e}-04$ & \multirow{2}{*}{$4.29 \mathrm{e}-08$} & 10.62 \\
\hline & & Post-test & $1.93 \mathrm{e}-06$ & & 89.38 \\
\hline & \multirow{2}{*}{ SUS-Card Delivery } & Pre-test & $7.81 \mathrm{e}-05$ & \multirow{2}{*}{$3.87 \mathrm{e}-09$} & 7.45 \\
\hline & & Post-test & $5.04 \mathrm{e}-07$ & & 92.55 \\
\hline \multirow{8}{*}{$\begin{array}{c}\text { The } \\
\text { PROUNI } \\
\text { Scholarship }\end{array}$} & \multirow{2}{*}{ Get and Separate Documents } & Pre-test & $1.54 \mathrm{e}-02$ & \multirow{2}{*}{$8.85 \mathrm{e}-10$} & 0.00 \\
\hline & & Post-test & $3.96 \mathrm{e}-05$ & & 100.00 \\
\hline & \multirow{2}{*}{ Check Student Profile } & Pre-test & $1.19 \mathrm{e}-02$ & \multirow{2}{*}{$3.28 \mathrm{e}-08$} & 4.64 \\
\hline & & Post-test & $6.90 \mathrm{e}-04$ & & 95.36 \\
\hline & \multirow{2}{*}{ Select Scholarship Type } & Pre-test & $2.64 \mathrm{e}-02$ & \multirow{2}{*}{$4.23 \mathrm{e}-09$} & 2.72 \\
\hline & & Post-test & $3.38 \mathrm{e}-07$ & & 97.28 \\
\hline & \multirow{2}{*}{ Get Scholarship Term } & Pre-test & $2.85 \mathrm{e}-05$ & \multirow{2}{*}{$7.02 \mathrm{e}-10$} & 0.00 \\
\hline & & Post-test & $9.79 \mathrm{e}-05$ & & 100.00 \\
\hline
\end{tabular}

costs and effort for using the method still need to be measured, as well as further studies on a broader variety of processes must be conducted.

In addition to the games presented in this article, several other game prototypes were developed. These various design cycles allowed us to raise some issues. One of them was particularly interesting because the designer decided to include the possibility of the player killing the public servant responsible for providing the desired service as the final game scene. Killing the "boss" (the great enemy in a game) is a widespread action in digital games, and the designer naturally implemented it into his game. This fact warned us about the importance of opening a new research path discussing the games' design concerning the values involved in the game and the public service $[24,65]$.

(2) "Can these games increase citizens' understanding of public service delivery?"

Our preliminary experiments show that players understood the process, particularly the process activities and how the organization performs them to provide the public service. Statistical analysis shows $95 \%$ confidence in this assertion. This result motivates the continuity of this research with proof of concepts in public organizations and the challenge of a greater diversity of citizens.

However, it is also essential to eventually discuss the known limitations of serious games for learning purposes. For instance, Persico et al. [63] and Passarelli et al. [61] argue that the assumption of learner enthusiasm from game-based learning is not always accurate. Sometimes, players are skeptical and resistant to serious games that are deemed less appealing than entertainment games. On the other hand, the authors mention the potential of games for developing players' social, cultural, and gender identity, with consequential positive effects on their 
ethical beliefs. Therefore, further investigation of improving public process-based digital games' gameplay, flow, and aesthetics is welcome.

\section{CONCLUSION}

This article argues that games can promote transparency of the public service process and citizens' understanding of them. Due to their learning and engagement characteristics, games with purpose were considered valuable and innovative tools for this goal. The possibility of designing public process-based digital games for discrete public services in Brazil was demonstrated through examples. Preliminary evaluations show that the games help players understand process execution aspects, contributing to bridging the gap between citizens and public services. Play Your Process presents a method and tool able to support designers in the systematic construction of these games with a purpose by supporting game designers in creating games without contradicting the business process and the public service.

Regarding social impacts, the Play Your Process method adopted in public organizations could help the systematic design of public service process-based digital games, leading citizens to play these games in their daily lives, like any other popular game. In this way, citizens would continue to spend their time in an everyday activity, and at the same time, would be learning about the public services they use or might need to use someday.

Considering that citizen participation, one of the main pillars of open government, is an increasing level endeavor, we argue that by understanding how the service is provided, i.e., its underlying process, citizens will be more willing to participate in public services process management and co-design. By receiving insights into service and its implications, citizens may find the motivation to participate. Ultimately, citizens should change the process, simulate distinct alternatives for its execution, or even change and adapt the process to suit their own specific needs. Those are all interesting research issues to be explored based on current results.

Further case studies and addressing public process values, and gameplay improvements are short-term research activities regarding future work. Additionally, we could envision the design of interaction mechanisms through which citizens could make suggestions and share impressions or experiences about public service use. It would also be interesting to consider multiplayer games design, allowing collaboration between players (citizens and public servants). Another work could be to use the games in participatory, co-production, and innovation initiatives within or outside the public organization.

\section{REFERENCES}

[1] Gustav Aagesen and John Krogstie. 2011. Service delivery in transformational government: Model and scenarios. Electronic Government, an International fournal (EG) 8, 2-3 (2011), 242-258. https://doi.org/10.1504/EG.2011.039839

[2] Clark C. Abt. 1987. Serious Games. University Press of America, Boston, MA.

[3] Waleed Afandi. 2016. Social business process modeling: Opportunities and challenges. In Hawaii University International Conferences, Vol. 86. 3868-3877. https://doi.org/10.1109/HICSS.2014.480

[4] Jose Aguilar, Francisco Javier Díaz Serna, Junior Altamiranda, Jorge Cordero, Danilo Chavez, and José Antonio Gutiérrez Mesa. 2019. Metrópolis: Un juego serio emergente en una ciudad inteligente. DYNA: Revista de la Facultad de Minas. Universidad Nacional de Colombia. Sede Medellín 211, 86 (2019), 215-224. https://doi.org/10.15446/dyna.v86n211.8086

[5] César Alfaro, Jose M. Lavın, Javier Gomez, and David Rios Rios Insua. 2015. ePBPM: A graphical language supporting interoperability of participatory process. In 2015 2nd International Conference on eDemocracy \& eGovernment (ICEDEG). IEEE, 98-103. https://doi.org/ 10.1109/ICEDEG.2015.7114474

[6] Reemiah Muneer ALotaibi, Muthu Ramachandran, Ah-Lian Kor, and Amin Hosseinian-Far. 2016. Factors affecting citizens' use of social media to communicate with the government: A proposed model. The Electronic fournal of e-Government 14, 1 (2016), 60-72.

[7] Lorin W. Anderson and Benjamin Samuel Bloom. 2001. A Taxonomy for Learning, Teaching, and Assessing: A Revision of Bloom's Taxonomy of Educational Objectives. Longman.

[8] Renata Araujo and Yehia Taher. 2014. Refining IT requirements for government-citizen co-participation support in public service design and delivery. In Conference for E-Democracy and Open Government, Krems: DonauUniversität Krems, Vol. 1. 61-72.

[9] Victor R. Basili. 1992. Software Modeling and Measurement: The goal/question/metric paradigm. University of Maryland. Technical Report. CS-TR-2956, UMIACS-TR-92-96. 
[10] Nigan Bayazit. 2004. Investigating design: A review of forty years of design research. Design Issues 20, 1 (2004), 16-29. https://doi.org/ 10.1162/074793604772933739

[11] Jörg Becker, Lars Algermissen, and Thorsten Falk. 2012. Modernizing Processes in Public Administration: Process Management in the Age of e-Government and New Public Management. Springer-Verlag, Berlin,.

[12] Daniel Belanche, Luis Vicente Casaló, and Miguel Guinaliu. 2012. How to make online public services trustworthy. Electronic Government, an International fournal (EG) 9, 3 (2012), 291-308. https://doi.org/10.1504/EG.2012.048004

[13] Lamyae Bennis and Said Benhlima. 2015. Comparative study of the process model of Serious game design through the generic model DICE. In 2015 Intelligent Systems and Computer Vision (ISCV). IEEE, 1-5. https://doi.org/10.1109/ISACV.2015.7105539

[14] Irene Bernhard, Livia Norström, Ulrika Lundh Snis, Urban Gråsjö, and Martin Gellerstedt. 2018. Degree of digitalization and citizen satisfaction: A study of the role of local e-government in sweden. Electronic fournal of e-Government 16 (2018), 59-71

[15] Nitesh Bharosa, Marjin Janssen, Bram Klievink, Anne Fleur van Veenstra, and Sietse Overbeek. 2010. Guiding integrated service delivery: Synthesizing and embedding principles using role-playing games. Electronic fournal of e-Government 8, 2 (2010), 83-92.

[16] Emma Blomkamp. 2017. Co-design for government: Magic bullet or magical thinking?. In Proceedings of the 3rd International Conference on Public Policy (ICPP3). 1-25.

[17] Peter Bradwell and Sarah Marr. 2017. Making the most of collaboration an international survey of public service co-design. Annual Review of Policy Design 5, 1 (2017), 1-27.

[18] Mohamed Buheji. 2019. Re-inventing public services using gamification approaches. International fournal of Economics and Financial Issues 9, 6 (2019), 48-59. https://doi.org/10.32479/ijefi.8803

[19] Volkan Çağdaş and Erik Stubkjær. 2011. Design research for cadastral systems. Computers, Environment and Urban Systems 35, 1 (2011), 77-87. https://doi.org/10.1016/j.compenvurbsys.2010.07.003

[20] Leon Caluwé, Jac Geurts, and Wouter Jan Kleinlugtenbelt. 2012. Gaming research in policy and organization: An assessment from The Netherlands. Simulation \& Gaming 43, 5 (2012), 600-626. https://doi.org/10.1177/1046878112439445

[21] Donald T. Campbell and Julian C. Stanley. 2015. Experimental and Quasi-experimental Designs for Research. Ravenio Books.

[22] Claudia Cappelli, Julio Cesar Sampaio do Prado Leite, and Antonio de Padua Albuquerque Oliveira. 2007. Exploring business process transparency concepts. In 15th IEEE International Requirements Engineering Conference (RE 2007). IEEE, 389-390. https://doi.org/10. 1109/RE.2007.35

[23] CGI.Br. 2018. ICT Electronic Government 2017: Survey on the Use of Information and Communication Technologies in the Brazilian Public Sector. https://www.cetic.br/media/docs/publicacoes/2/TIC_eGOV_2017_livro_eletronico.pdf. Online. Accessed 21 July 2020.

[24] Tadeu Moreira de Classe, Renata Mendes de Araujo, Geraldo Bonorino Xexéo, and Sean Siqueira. 2019. The Play Your Process method for business process-based digital game design. International fournal of Serious Games 6, 1 (2019), 27-48. https://doi.org/10.17083/ijsg. v6i1.269

[25] Francesca De Filippi, Cristina Coscia, Guido Boella, Alessio Antonini, Alessia Calafiore, Anna Cantini, Roberta Guido, Carlo Salaroglio, Luigi Sanasi, and Claudio Schifanella. 2016. MiraMap: A we-government tool for smart peripheries in smart cities. IEEE Access 4 (2016), 3824-3843. https://doi.org/10.1109/ACCESS.2016.2548558

[26] Bruna Diirr, Renata Araujo, and Claudia Cappelli. 2014. Encouraging society participation through conversations about public service processes. International fournal of Electronic Government Research (IfEGR) 10, 2 (2014), 22-42. https://doi.org/10.4018/ijegr.2014040103

[27] Antonio Claret dos Santos, André Luiz Zambalde, Ricardo Braga Veroneze, Giancarla Aparecida Botelho, and Paulo Henrique de Souza Bermejo. 2015. Open innovation and social participation: A case study in public security in Brazil. In International Conference on Electronic Government and the Information Systems Perspective. Springer, 163-176. https://doi.org/10.1007/978-3-319-22389-6_12

[28] Marlon Dumas, Marcello La Rosa, Jan Mendling, and Hajo A. Reijers. 2013. Business Process Management. Springer.

[29] Priscila Engiel, Renata Araujo, and Claudia Cappelli. 2014. Designing public service process models for understandability. Electronic fournal of e-Government 12, 1 (2014), 95-111.

[30] Enzo Falco and Reinout Kleinhans. 2018. Beyond information-sharing. a typology of government challenges and requirements for two-way social media communication with citizens. Electronic fournal of e-Government 16, 1 (2018).

[31] S. P. Gayialis, G. A. Papadopoulos, S. T. Ponis, P. Vassilakopoulou, and I. P. Tatsiopoulos. 2016. Integrating process modeling and simulation with benchmarking using a business process management system for local government. International fournal of Computer Theory and Engineering 8, 6 (2016), 482. https://doi.org/10.7763/IJCTE.2016.V8.1093

[32] Yiwei Gong and Marijn Janssen. 2017. The impact of social business process management on policy-making in e-government. In Proceedings of the 50th Hawaii International Conference on System Sciences. 2458-2467. https://doi.org/10.24251/HICSS.2017.29

[33] GOV.Br. 2018. Obter bolsa de estudo do ProUni (ProUni) - (English title: How to get a PROUNI's scholarship). https://www.servicos. gov.br/servico/obter-bolsa-de-estudo-do-prouni. Online. Accessed 21 July 2020.

[34] GOV.Br. 2019. Governo do Brasil. Estratégia de Governança Digital 2019 - In English: Brazilian Government, Digital Governance Strategy 2019. https://www.gov.br/governodigital/pt-br/estrategia-de-governanca-digital. Online. Accessed 21 July 2020.

[35] GOVINT. 2019. Co-Production - How does the Co-Production Star toolkit help you? http://www.govint.org/our-services/coproduction/. Online. Accessed 21 July 2020. 
[36] Åke Grönlund. 2009. ICT is not participation is not democracy-eParticipation development models revisited. In International Conference on Electronic Participation. Springer, 12-23. https://doi.org/10.1007/978-3-642-03781-8_2

[37] Juho Hamari, Jonna Koivisto, and Harri Sarsa. 2014. Does gamification work?-a literature review of empirical studies on gamification. In 2014 47th Hawaii International Conference on System Sciences. Ieee, 3025-3034. https://doi.org/10.1109/HICSS.2014.377

[38] Lobna Hassan. 2017. Governments should play games: Towards a framework for the gamification of civic engagement platforms. Simulation \& Gaming 48, 2 (2017), 249-267. https://doi.org/10.1177/1046878116683581

[39] Alan Hevner, Salvatore March, Jinsoo Park, and Sudha. Ram. 2004. Design science in information systems research. MIS Quarterly 28, 1 (2004), 75-105.

[40] ICRC. 2018. Brasil: 82.094 pessoas registradas como desaparecidas em 2018: famílias precisam de respostas" (English title: Brazil: 82,094 people registered as missing in 2018: families need answers). https://www.icrc.org/pt/document/brasil-82094-pessoas-registradascomo-desaparecidas-em-2018-familias-precisam-de-respostas. Online. Accessed 21 July 2020.

[41] Tuula Jäppinen. 2015. How to manage a service innovation process in the public sector: from co-design to co-production. In The Handbook of Service Innovation. Springer, 707-726.

[42] Luiz Antonio Joia. 2004. Bridging the digital divide: Some initiatives in Brazil. Electronic Government, an International fournal 1, 3 (2004), 300-315. https://doi.org/10.1504/EG.2004.005554

[43] Fernando Kleiman. 2018. Winning Data Game. https://wdgame.home.blog/. Online. Accessed 24 February 2021.

[44] Fernando Kleiman. 2019. Engaging governments in open data policies through gaming. In Proceedings of the 12th International Conference on Theory and Practice of Electronic Governance (ICEGOV2019). 461-464. https://doi.org/10.1145/3326365.3326426

[45] Fernando Kleiman, Marijn Janssen, Sebastiaan Meijer, and Sylvia JT Jansen. 2020. Changing civil servants' behaviour concerning the opening of governmental data: Evaluating the effect of a game by comparing civil servants' intentions before and after a game intervention. International Review of Administrative Sciences (2020), 1-22. https://doi.org/10.1177/0020852320962211

[46] Andrej Kovačič. 2007. Process-based knowledge management: Towards e-Government in Slovenia. Management: fournal of Contemporary Management Issues 12, 1 (2007), 45-64.

[47] Bahar Kutun and Werner Schmidt. 2019. BPMN Wheel: Board game for business process modelling. In European Conference on Games Based Learning. Academic Conferences International Limited, 1008-XVIII.

[48] Ilpo Laitinen, Tony Kinder, and Jari Stenvall. 2018. Co-design and action learning in local public services. Fournal of Adult and Continuing Education 24, 1 (2018), 58-80. https://doi.org/10.1177/1477971417725344

[49] Liz Lanier. 2019. Video Games Could Be a $\$ 300$ Billion Industry by 2025. https://variety.com/2019/gaming/news/video-games-300billion-industry-2025-report-1203202672/. Online. Accessed 21 July 2020.

[50] Stavros Lounis, Katerina Pramatari, and Aristeidis Theotokis. 2014. Gamification is all about fun: The role of incentive type and community collaboration. In Proceedings of the European Conference on Information Systems. Association for Informatio Systems, 1-14.

[51] Jane McGonigal. 2011. Reality is Broken: Why Games Make us Better and How They Can Change the World. Penguin.

[52] David R Michael and Sandra L Chen. 2005. Serious Games: Games that Educate, Train, and Inform. Muska \& Lipman/Premier-Trade.

[53] Brazilian Health Ministry. 2019. Cartão Nacional de Saúde - (In English: Health Care National Card). https://www.saude.gov.br/acoese-programas/cartao-nacional-de-saude/sobre-o-programa. Online. Accessed 21 July 2020.

[54] Valeria Esther Nigri Musafir and Christiana Soares de Freitas. 2015. Strategies, policies and evaluations of brazilian electronic government. Electronic fournal of E-Government 13, 2 (2015), 122-135.

[55] Nadim Nachar et al. 2008. The mann-whitney u: A test for assessing whether two independent samples come from the same distribution. Tutorials in Quantitative Methods for Psychology 4, 1 (2008), 13-20. https://doi.org/10.20982/tqmp.04.1.p013

[56] United Nations. 2018. UN E-Government Survey". Department of Economic and Social Affairs). https://publicadministration.un.org/ en/research/un-e-government-surveys. Online. Accessed 21 July 2020.

[57] Björn Niehaves and Robert Malsch. 2009. Democratizing process innovation? On citizen involvement in public sector BPM. In International Conference on Electronic Government. Springer, 245-256. https://doi.org/10.1007/978-3-642-03516-6_21

[58] OECD. 2020. Digital Government. http://www.oecd.org/gov/digital-government/. Online. Accessed 21 July 2020

[59] OGP. 2020. Open Government Partnership. https://www.opengovpartnership.org/members/brazil/. Online. Accessed 21 July 2020.

[60] Paolo Pariso and Alfonso Marino. 2020. From digital divide to e-government: Re-engineering process and bureaucracy in public service delivery. Electronic Government, an International fournal 16, 3 (2020), 314-325.

[61] Marcello Passarelli, Francesca Dagnino, Jeffrey Earp, Flavio Manganello, Donatella Persico, Francesca Pozzi, Chris Bailey, Carlo Perrotta, Thomas Buijtenweg, and Mata Haggis. 2019. Educational games as a motivational tool: Considerations on their potential and limitations. In Proceedings of the 11th International Conference on Computer Supported Education - Volume 1: CSEDU, ISBN 978-989-758367-4. 330-337. https://doi.org/10.5220/0007586503300337

[62] Ken Peffers, Tuure Tuunanen, Marcus A Rothenberger, and Samir Chatterjee. 2007. A design science research methodology for information systems research. Journal of Management Information Systems 24, 3 (2007), 45-77.

[63] Donatella Persico, Marcello Passarelli, Francesca Dagnino, Flavio Manganello, Jeffrey Earp, and Francesca Pozzi. 2019. Games and learning: Potential and limitations from the players' point of view. In Games and Learning Alliance. GALA 2018. Lecture Notes in Computer Science, Gentile M., Allegra M., Söbke H. (Eds.), Vol 11385. Springer.

Digital Government: Research and Practice, Vol. 2, No. 4, Article 32. Publication date: December 2021. 
[64] Panagiotis Petridis, Kyriaki Hadjicosta, Victor Guang Shi, Ian Dunwell, Timothy Baines, Ali Bigdeli, Oscar F Bustinza, and Victoria Uren. 2015. State of the art in business games. International fournal of Serious Games 2, 1 (2015). https://doi.org/10.17083/ijsg.v2i1.54

[65] Nicolas Pflanzl, Tadeu Classe, Renata Araujo, and Gottfried Vossen. 2016. Designing serious games for citizen engagement in public service processes. In International Conference on Business Process Management. Springer, 180-191. https://doi.org/10.1007/978-3-31958457-7_14

[66] Nicolas Pflanzl and Gottfried Vossen. 2013. Human-oriented challenges of social BPM: an overview. In Enterprise Modelling and Information Systems Architectures (EMISA 2013). Gesellschaft fur Informatik e.V., 163-176.

[67] Nicolas Pflanzl and Gottfried Vossen. 2018. What do business process modelling and super mario bros. have in common? A gamesperspective on business process modelling. Enterprise Modelling and Information Systems Architectures (EMISAf). International fournal of Conceptual Modeling (2018), 69-76. https://doi.org/10.18417/emisa.si.hcm.7

[68] Mariano Pimentel, Denise Filippo, and Thiago Marcondes Santos. 2020. Design science research: pesquisa científica atrelada ao design de artefatos.RE@ D-Revista de Educação a Distância e Elearning 3, 1 (2020), 37-61. https://doi.org/10.34627/re@d_le@d.v3i1.203

[69] Alenka Poplin. 2011. Games and serious games in urban planning: Study cases. In International Conference on Computational Science and Its Applications. Springer, 1-14. https://doi.org/10.1007/978-3-642-21887-31

[70] PROUNI. 2018. Programa Universidade Para Todos - (English title: PROUNI - University for Everyone Program). http://prouniportal mec.gov.br. Online. Accessed 21 July 2020

[71] Mohammad Ehson Rangiha and Bill Karakostas. 2013. Towards a meta-model for goal-based social BPM. In International Conference on Business Process Management. Springer, 104-112. https://doi.org/10.1007/978-3-319-06257-0_9

[72] Cláudia Ribeiro, João Fernandes, André Lourenço, José Borbinha, and João Pereira. 2012. Using serious games to teach business process modeling and simulation. In Proceedings of the International Conference on Modeling, Simulation and Visualization Methods (MSV). The Steering Committee of The World Congress in Computer Science.

[73] David L Rogers. 2016. The Digital Transformation Playbook: Rethink your Business for the Digital Age. Columbia University Press.

[74] Margarida Romero, Mireia Usart, and Michela Ott. 2015. Can serious games contribute to developing and sustaining 21st century skills? Games and Culture 10, 2 (2015), 148-177. https://doi.org/10.1177/1555412014548919

[75] Kristina Rosenthal and Stefan Strecker. 2018. Business process modelling as serious game: Findings from a field study. Research Papers 165 (2018). https://aisel.aisnet.org/ecis2018_rp/165.

[76] Marco Santorum. 2011. A serious game based method for business process management. In Fifth International Conference on Research Challenges in Information Science (RCIS). IEEE, 1-12. https://doi.org/10.1109/RCIS.2011.6006843

[77] Hígor Ricardo Monteiro Santos, George Augusto Valença, and Carina Frota Alves. 2015. Strategies for managing critical success factors of BPM initiatives in brazilian public organizations: A qualitative empirical study. iSys - Brazilian fournal of Information Systems 8, 1 (2015), 42-64. https://doi.org/10.5753/isys.2015.279

[78] Frank Schönthaler, Gottfried Vossen, Andreas Oberweis, and Thomas Karle. 2012. Business Processes for Business Communities. Springer.

[79] William R Shadish, Thomas D Cook, Donald Thomas Campbell, et al. 2002. Experimental and Quasi-experimental Designs for Generalized Causal Inference/William R. Shedish, Thomas D. Cook, Donald T. Campbell. Boston: Houghton Mifflin,.

[80] Samuel Sanford Shapiro and Martin B Wilk. 1965. An analysis of variance test for normality (complete samples). Biometrika 52, 3/4 (1965), 591-611. https://doi.org/10.2307/2333709

[81] Herbert A Simon. 2019. The Sciences of the Artificial. MIT press.

[82] Kirsty Strokosch and Stephen P Osborne. 2020. Debate: If citizen participation is so important, why has it not been achieved? Public Money \& Management 40, 1 (2020), 8-10. https://doi.org/10.1080/09540962.2019.1654322

[83] Sarah-Kristin Thiel, Michaela Reisinger, Kathrin Röderer, and Peter Fröhlich. 2016. Playing (with) democracy: A review of gamified participation approaches. FeDEM-efournal of eDemocracy and Open Government 8, 3 (2016), 32-60. https://doi.org/10.29379/jedem.v8i3 440

[84] Jakob Trischler, Timo Dietrich, and Sharyn Rundle-Thiele. 2019. Co-design: from expert-to user-driven ideas in public service design. Public Management Review 21, 11 (2019), 1595-1619. https://doi.org/10.1080/14719037.2019.1619810

[85] Amy Van Looy and Joachim Van den Bergh. 2018. The effect of organization size and sector on adopting business process management. Business \& Information Systems Engineering 60, 6 (2018), 479-491. https://doi.org/10.1007/s12599-017-0491-3

[86] András Vargha, Tamas Rudas, Harold D Delaney, and Scott E Maxwell. 1996. Dichotomization, partial correlation, and conditional independence. Journal of Educational and Behavioral statistics 21, 3 (1996), 264-282. https://doi.org/10.2307/1165272

[87] Luis Von Ahn. 2006. Games with a purpose. Computer 39, 6 (2006), 92-94. https://doi.org/10.1109/MC.2006.196

[88] Michael Winter, Rüdiger Pryss, Thomas Probst, and Manfred Reichert. 2020. Learning to read by learning to write: Evaluation of a serious game to foster business process model comprehension. FMIR Serious Games 8, 1 (2020), e15374. https://doi.org/10.2196/15374

[89] Hanna Wirman. 2018. Serious games as social innovation: Case Hong Kong 2003-2017. Cubic fournal 1, 1 (2018), 186-195. https: //doi.org/10.31182/cubic.2018.1.011

[90] Claes Wohlin, Per Runeson, Martin Höst, Magnus C Ohlsson, Björn Regnell, and Anders Wesslén. 2012. Experimentation in Software Engineering. Springer Science \& Business Media. 
[91] Kaifeng Yang and Kathe Callahan. 2007. Citizen involvement efforts and bureaucratic responsiveness: Participatory values, stakeholder pressures, and administrative practicality. Public Administration Review 67, 2 (2007), 249-264. https://doi.org/10.1111/j.1540-6210.2007. 00711.x

[92] Yueping Zheng. 2017. Explaining citizens' E-participation usage: Functionality of e-participation applications. Administration \& Society 49, 3 (2017), 423-442. https://doi.org/10.1177/0095399715593313

Received December 2020; revised July 2021; accepted July 2021 